\title{
Reclaiming Self-care: Self-care as a Social Justice Tool for Black Wellness
}

\author{
Janan P. Wyatt ${ }^{1}$ D. Gifty G. Ampadu ${ }^{2}$
}

Received: 18 December 2020 / Accepted: 19 August 2021 / Published online: 3 September 2021

(c) The Author(s), under exclusive licence to Springer Science+Business Media, LLC, part of Springer Nature 2021

\begin{abstract}
Black communities face multiple stressors including racism, discrimination, and navigating systems of oppression, all of which affect their mental health and wellbeing. In recent years, the practice of self-care has gained popularity as a strategy to cope with stress and to improve overall health. However, the current discourse often focuses on individual self-care behaviors and excludes systemic and community level factors that encourage, sustain, or inhibit self-care practices. This paper contextualizes a conceptual model of self-care with intersectionality theory and the psychology of liberation framework, in relation to the lived experiences of Black communities. The paper aims to underscore the necessity of self and community care as a tool for social justice, preservation, and resistance against oppressive systems that threaten the mental health and wellness of this community.
\end{abstract}

Keywords Black $\cdot$ Self-care $\cdot$ Social justice $\cdot$ Mental health $\cdot$ Wellness $\cdot$ Activism

\section{Introduction}

Globally, Black communities continue to face multiple stressors including racism and navigating systems of oppression that hinder their wellbeing and undoubtedly influence mental health functioning and outcomes. Mental health research continues to identify the harmful effects of racism and discrimination, and further underscores racism as a social determinant of health (Krieger, 2000; Paradies, 2006; Pascoe \& Smart Richman, 2009; Williams et al., 2003). Other stressors that disproportionally impact Black communities include economic and educational inequality, mass incarceration, racialized policing, and the killing of Black people by the hand of law enforcement (APA, 2020). Most recently, the COVID-19 pandemic, and the global outcry about the oppression and continued mistreatment of Black individuals and communities has propelled

Janan P. Wyatt

Janan.Wyatt@yale.edu

1 Department of Psychiatry, Yale School of Medicine, Program for Recovery and Community Health, Erector Square, 319 Peck St., Bldg. 1, New Haven, CT 06513, USA

2 Department of Psychiatry and Behavioral Sciences, Montefiore Medical Center, 3340 Bainbridge Ave., Bronx, NY 10467, USA conversations about self-care as a medium for coping with the detrimental psychological effects of racial oppression and discrimination.

The current literature regarding self-care is often centered around improving the self and restoring balance within the self (Denyes et al., 2001; Kinser et al., 2016). Missing from the current self-care discourse is the necessity for minoritized groups to engage in self-care as means of thriving within spaces and systems that continue to harm their personhood and communal existence. Within many marginalized communities, self-care has political and social justice roots that cannot afford to be ignored. When examined through a historical and socio-political lens, self-care is, and has always been, a tool for social justice in efforts to resist the oppressive systems that threaten the health and wellness of Black people. This can be seen through examples of the Black Panther Party and their launch of initiatives promoting community health such as the free breakfast program and organizing community clinics for medical care (Heynen, 2009).

The authors of this paper aim to apply and contextualize an ecological model of self-care developed by Miller et al. (2019) as applicable to the self-care needs of Black individuals and communities. Our application of Miller and colleagues' model is informed by the theory of intersectionality and the psychology of liberation (Carbado et al., 2013; 
Crenshaw, 1989; Miller et al., 2019; Prilleltensky, 2003). These theoretical frameworks include a foundational element of raising awareness and critical consciousness about the impact of oppression among marginalized people. This increased consciousness may orient Black people to the necessity of self-care, increase self-care practices, and create a pathway to improved well-being. We conclude our paper with recommendations for future research and communitybased practical implications.

\section{Self-care}

There is not a clear consensus on the definition of self-care within the health literature. Self-care has been defined in various ways within multiple disciplines to communicate the importance of caring for oneself. Within the medical domain, self-care has been described as activities performed by an individual directed at improving or promoting overall health or general wellbeing (Bickley, 1998; Richard \& Shea, 2011; Lipson \& Steiger, 1996; Myers et al., 2012). Grantz (1990) suggests that self-care is influenced by cultural norms or context, specific to the individual and that self-efficacy, sense of control, knowledge, and values also impact our ability to initiate self-care. Carter and Barnett (2014) further indicate that practicing self-care involves one's ability to engage in self-awareness and self-regulation as tools to develop a balance between physical, psychological, and spiritual needs. Self-care has been a recommended intervention to minimize professional burnout and compassion fatigue, and to facilitate coping with work-related stress, especially among trainees in the helping profession (Figley, 2002; Sherman 2004; Skovholt \& Rønnestad, 2003; Dorociak et al., 2017; Wise et al., 2012). Research suggests that continual engagement in self-care is associated with numerous health benefits, such as improved physical health, decreased psychological distress, general life satisfaction, and career-based satisfaction (Richard \& Shea, 2011; Shapiro et al., 2007; Skovholt et al., 2001).

To date, much of the literature on self-care behavior is related to recharging and restoring the self, and has focused on practitioners, given their role as caregivers to vulnerable populations (Harris, 2017; Figley, 2002; Kravits et al., 2010; Skovholt \& Rønnestad, 2003; Sanchez-Reilly et al., 2013). Practitioners are encouraged to engage in self-care as a means of preserving themselves and to maintain the professional integrity of their work, considering their exposure to the emotional traumas of their clients (Harris, 2017; Figley, 2002; Skovholt \& Rønnestad, 2003; Sanchez-Reilly et al., 2013). This is well documented in the literature on vicarious trauma, where self-care has been identified as a healthy buffer to this risk among practitioners (Bell et al., 2003; Newell \& MacNeil, 2010; Pearlman \& Saakvitne, 1995). The literature has also most recently focused on the importance of self-care among mental health trainees across various disciplines, including psychology, social work, and nursing (Barnett, 2014; Carroll et al., 1999; Posluns \& Gaill 2020; Shapiro et al., 2007).

Within the general public, self-care is often discussed and illustrated as individual activities performed to "treat" oneself (Kinser et al., 2016). Unfortunately, this, in combination with a growing wellness industry, perpetuates a culture of self-care based on individualism, capitalism, and consumerism (Hobart \& Kneese, 2020). However, for Black people and communities that are exposed to the harsh realities of being second class global citizens subjected to oppression, self-care can go beyond "treating" oneself. Oftentimes, the literature on self-care in Black communities has focused on self-care as an intervention to mediate the progression of medical conditions such as diabetes, hypertension, and cardiovascular disease (Evans-Hudnall et al., 2014; Ruggiero et al., 2014, Sisk et al., 2006; Warren-Findlow \& Seymour, 2011). There appears to be a dearth in the literature about the importance and necessity of self-care as a holistic wellness practice for Black people, that also includes attending to our mental health and wellbeing.

\section{Radical self-care}

The mainstream view of self-care in both scientific and lay communities appear to be exclusive and decontextualized, leading rise to the concept and practice of radical self-care. Radical self-care can be traced back to the scholarship of Black and Latinx feminists such as bell hooks, Audre Lorde, and Gloria Anzaldua (Anzaldúa, 1987; Hobart \& Kneese, 2020; Hooks, 1993; Lorde, 1988; Nicol \& Yee, 2017; Nayak, 2020) and has been viewed as a tool for social justice and survival for marginalized communities. Radical self-care has historical roots and was seen as a much-needed practice among activists who sought to propel social justice efforts while preserving their wellbeing (Lorde, 1988; Sheehy \& Nayak, 2020). More typically, radical self-care as a Black feminist ideology/praxis has denoted a necessitated self-care act rooted in the principles of self-determination, self-preservation, and self-restoration (Hooks, 1993; Lorde, 1988; Hill Collins, 2000).

The literature on radical self-care further asserts that selfcare engagement among Black individuals and communities is political in nature (Hill Collins, 2000; Lorde, 1984; Lorde, 1988; Harris, 2017). Michaeli (2017) notes that radical self-care is political because it recognizes that the "self" "is grounded in particular political histories and present situations of violence and vulnerability" (p. 53). Moreover, selfcare is political because it challenges historical notions and assumptions that Black people lack the capacity to care for themselves. When practiced in Black communities, self-care is often executed as resistance to conditions of inequality, 
marginalization, and minoritization (Hobart \& Kneese, 2020). Radical self-care also recognizes that the individual and the community have a reciprocal relationship. Such that, the individual that is embedded within the community is affected by the events of that community, and vice versa.

Therefore, the need for radical self-care is prompted by the embedded intersections of social identities in which many people of color find themselves. In her work about self-care and women of color in the social work field, Nayak (2020) argues that the typical way of approaching self-care behaviors "advocate strength-based practice and asset-based approaches," which lack a nuanced understanding of the impact of intersectional identities on self-care choices. As described by Nicol and Yee (2017), radical self-care:

Involves practices that keep us physically and psychologically healthy and fit, making time to reflect on what matters to us, challenging ourselves to grow and checking ourselves to ensure that what we are doing aligns with what matters to us... Practiced faithfully radical self-care involves owning and directing our lives and choosing with whom, how, and how often we engage in our nested, interconnected worlds that we can be unapologetically ourselves in the face of unrelenting pressure and expectations to be otherwise (p. 134).

With these thoughts in mind, we assert that Black people's desire and audacity to engage in self-care is always radical in nature. Thus, sustainable self-care practices should be accessible in various levels of the individual and community ecology.

\section{Theoretical Frameworks for Self-care in Black Communities}

As we advocate a more inclusive model of self-care that responds to the specific needs and strengths of Black communities', we contextualize radical self-care within the theory of intersectionality and the psychology of liberation. We recognize the political roots and highlight the definition of "radical" as an ideology or belief system that asserts that total transformative change is imperative in reducing social problems (Dictionary of Politics \& Government, 2004) that minoritized communities experience. With this definition in mind, the practice of self-care to resist their dehumanization, is a radical act. Furthermore, self-care models that center on the health and wellness of Black people also become radical in nature given that they are a part of a society that threatens their well-being. These two theoretical frameworks provide a sociocultural and social justice awareness that guides us toward a self-care model responsive to culture and moves us closer to healing.

\section{Theory of Intersectionality}

Kimberly Crenshaw's theory of intersectionality is a conceptual framework of understanding an individual and how their multiple identities are connected. Intersectionality considers Black feminist and critical race ideologies (Carbado et al., 2013; Crenshaw, 1989), offering insight into how layers of social identity based on race, gender, class, sexuality, ability, and socioeconomic status can further marginalize individuals. When an intersectionality framework is utilized, we can better understand how individuals navigate their world and how others perceive them, further shaping their worldview. Without this framework, an analysis of oppression is understood via one, singular lens, ignoring other identities that shape the individual's experiences, particularly experiences of oppression. Intersectionality allows for identifying how all forms of oppression (e.g., racism, classism, sexism) interconnect and maintain inequality for Black people. The ability to recognize that we all have intersecting identities allows us to validate our lived experiences fully. Self-care practices are limited and incomplete when they do not attend to the wellbeing of "whole" selves, including all identities and their unique needs.

\section{Psychology of Liberation}

As a theory and framework, liberation psychology outlines how people understand, resist, and overcome oppression to achieve psychological well-being (Prilleltensky, 2003). Prilleltensky argues that psychological and political dimensions are interconnected, and that individuals' wellbeing is rooted in these contexts. He further asserts that the liberation of oppressed people has both psychological and political impact, such that the liberation for the individual is interconnected with the liberation of larger groups and communities. Prilleltensky underscored the notion of critical consciousness and states, "It is only when the oppressed attain a certain degree of conscientization that mechanisms of resistance take place" (Prilleltensky, 2003; Prilleltensky \& Nelson, 2002). Conscientization is a central tenant in liberation psychology, highlighting that the liberation of oppressed people begins with a critical understanding of how they are oppressed. This awareness then becomes a tool for psychological liberation as they develop strategies to resist systems of oppression (French et al., 2020), such as self-care practices. Taken together, liberation psychology centers on experiences of oppression and its negative psychological effects on people and communities while also "identifying the ways people thrive" under oppressive socio-political conditions (French et al., 2020; Rivera, 2020). Utilizing the framework of liberation psychology, we assert that one of the ways Black people thrive in the face of oppression is through the practice of radical self-care. 


\section{Conceptual Model of Self-care}

Usually, self-care is discussed as a set of behaviors and strategies that one can engage in to improve or sustain their health status (Miller et al., 2019; Miller, 2020). Common recommendations of self-care behaviors include improving sleep hygiene, increasing exercise, consuming nutritious foods, and attending to medical needs and appointments (Myers et al., 2012; Posluns \& Gall, 2020). Other common understandings of self-care can include building interpersonal boundaries, taking breaks, or enjoying pleasurable activities (Barnett, 2014; Barnett \& Cooper, 2009). While all these examples constitute self-care, there is a primary focus on the specified action or behavior. Conceptualizing self-care only as action-oriented items, limits the comprehensive understanding and necessity of self-care for wellness. Expanding our understanding and ideas of self-care allows for more flexibility in both thought and practice (Miller, 2020). One consequence of solely focusing on selfcare as behaviors can propel self-care stereotypes, such as when one "should" practice self-care. Additionally, hyperfocusing on self-care behaviors has the potential to trap one in the consumerism spirit that saturates the current discourse surrounding self-care, such as "treat yourself!". Expanding the construct and conceptualization of self-care can help debunk the messaging about who needs, has access to, and deserves self-care.

We propose that the conceptual model of self-care created by Miller et al. (2019) provides a comprehensive understanding of self-care and can be applied to Black individuals and communities. This model was created with vulnerable populations in mind that face multiple stressors, such as foster parents, queer communities, and graduate students of color in the mental health profession (Miller et al., 2019; Miller, 2020). This model offers a more nuanced understanding of self-care that extends beyond the idea of self-care simply being action behaviors. We believe that this model can be applied to promoting self-care within Black communities by offering attention to the factors that facilitate or hinder self-care within these communities. As the model highlights, self-care behaviors are embedded in the process of both internal and external factors that strengthen self-care or foster self-neglect. This model allows for a shift from the limited perspective of self-care as a set of behaviors, to an in-depth understanding of self-care as a multi-layered process. Miller depicts this process in five layers, with each influencing the subsequent layer: self-care support, self-care orientation, self-care motivation, self-care skills, and selfcare behaviors.

\section{Self-care Support}

Miller et al. (2019) describe self-care support as the external factors influencing the practice and engagement in self-care. The concept of self-care support operates with the assumptions that individuals may not know what self-care is, how to engage in a self-care practice, or have accessible resources for executing a self-care plan. Consequently, self-care support includes measures such as providing information, training, and resources about self-care. From a systems perspective, self-care support requires systems, institutions, and communities to implement programs and/or initiatives that support individuals' self-care needs. Self-care support also requires that systems, institutions, and communities respond to the unique wellness needs of individuals. For example, a system that is supportive of self-care recognizes the impact of oppression and intersectional identities on the lived experiences of communities of color and how this can influence self-care practices. Self-care support can also take the form of community building that prioritizes increasing self-care capacities and sustainability within Black communities. Regarding community building for self-care, actions should consider "local cultural, health, and economic landscapes" (Subica et al., 2016) that can best meet the wellness needs of those it aims to serve. Examples of self-care support that foster community and capacity building can be demonstrated by local organizations coming together to build community gardens or farmers' markets. These are often seen in neighborhoods that have been considered "food deserts" and are created, so that community members have access to nutritious foods. Community self-care support can also look like community health advocates providing training on self-care and teaching community members about the importance of engaging in culturally-congruent self-care.

\section{Self-care Orientation}

Self-care orientation is about the perspective one holds about engaging in self-care and how that shapes prioritizing a self-care practice. In many Black communities, individuals may not be oriented to prioritizing self-care due to multiple factors. One cultural factor could be closely related to the focus on collectivism in communities of color in which individuals are other-oriented instead of self-oriented (Miller, 2020). This orientation to others is viewed as a strength in that individuals are often encouraged to help or support the needs of others or the community, sometimes above and beyond prioritizing the needs of self. The practice of collectivism was most recently evident in protests worldwide, where globally, communities of color gathered to protest publicly and speak out against police brutality among African Americans. Additionally, the notion "lift as you climb" further communicates this collective spirit that 
is often prevalent in communities of color, highlighting the idea that even though the burden of climbing is difficult, we are to help those around us still so that no one is left behind. Given the cultural focus on collectivism within the Black community, self-care engagement might be perceived as a conflict with collectivist values. For example, Black women are often identified as caretakers in their families and communities (Hill Collins, 1991) and as social activist leaders (Addai, 2020) for their communities. Even the caretaker role has historical roots. Enslaved African women were treated as commodified labor to take care of land, children, and families that did not belong to them. The caretaker role and identity for many women of color underscores that the focus on taking care of others is deeply ingrained, posing as a potential barrier towards a self-care orientation. The absence of a self-care orientation further allows one to delay or ignore their self-care needs. Research has supported the idea that individuals may feel guilt or believe that engaging in self-care is selfish (Brownlee, 2016). Operating from a place of cultural humility, positioning self-care as a necessary practice of community care/wellness can help promote self-care among Black individuals.

\section{Self-care Motivation}

Miller and colleagues also assert that individuals are best able to engage in a consistent self-care practice when the motivation to do so can be sustained. Self-care is a repeated practice that requires intention, rather than a one-time activity, thus, motivation is best understood as an internal factor that can facilitate this process. This notion is similar to theories of behavior change, which state that intending to participate in a healthy activity is insufficient to incite or maintain action Webb and Sheeran (2006). Therefore, educating and encouraging individuals to practice self-care due to its multiple wellness benefits is insufficient. Maintaining motivation to engage in healthy behaviors consistently is a barrier for many individuals (Rothman et al., 2011), but people of color are potentially at a heightened risk given competing priorities, leading to self-care as an afterthought. Coupled with an "other" orientation, which strengthens the misconception that others/the collective's needs are more important than self-needs, Black people might benefit from pre-selecting self-care activities to practice, in addition to identifying barriers that hinder self-care engagement. This could prove to be a useful practice for people seeking to increase or maintain motivation and sustainability Due to the collectivist nature within Black communities, individual motivation to engage in self-care can be generated from community resources. Community wellness programs are often founded with the spirit of social justice and seek to increase opportunities for people to engage in sustainable self-care activities with others in their community. Self-care taking place in the community space can serve as a major motivation for people to maintain wellness behaviors. Other factors that can interfere with maintaining motivation are stereotypes about self-care, especially ones that suggest we must earn self-care or that self-care is selfish. These stereotypes oppose the necessity of self-care and further supports the unhelpful idea that self-care is an act of indulgence or pampering (Miller, 2020) prompts individuals to ignore their wellbeing. Lastly, individuals must move away from the idea that productivity is priority, at the expense of our self-care needs (Nicol \& Yee, 2017), as this can also lead to a decrease in self-care motivation. A healthier, more sustainable understanding of self-care can also assist with motivation maintenance in that self-care is a practice intended for healing and wellbeing. Black people deserve to engage in consistent self-care because it is necessary for a thriving well-balanced life.

\section{Self-care Skills}

Self-care skills require a level of self-awareness, specifically regarding attention to our "emotional, cognitive, physical and spiritual state" (Miller et al., 2019, p. 11). The model suggests that this level of self-awareness can help individuals know when and how to best engage in self-care behaviors given their wellness needs. More specifically, self-care skills can help create strategic self-care plans that best attend to our wellbeing. Knowing when and how to execute self-care behaviors is a skill set that requires self-awareness coupled with practice. Given that self-care is not formulaic or a prescribed one model that fits all, individuals are encouraged to think of which specific self-care behaviors are necessary for them. This also requires self-care skills to recognize when one does not have the capacity to meet a self-care need. Miller further suggests that self-care skills may also require mindfulness skills. Practicing mindfulness to promote self-awareness helps to implement behaviors aligned with specific selfcare needs. Practicing mindfulness, such as meditation, is a self-care behavior in itself and has been demonstrated to reduce stress (Grossman et al., 2004; Janssen et al., 2018; Shapiro et al., 2007; Suleiman-Martos et al., 2020). Research has also highlighted the potential health benefits of practicing mindfulness for Black people (Biggers et al., 2020; Cotter \& Jones, 2020; Palta et al., 2012). In fact, there is a recent increase in technology products that cater to the wellness needs of Black people. Products such as Liberate, a phone applications for meditation "designed for the Black experience" offers guided meditations and opportunities for Black people to engage in community with others "to heal and be free"(Liberatemediation. com). This can be viewed as a more culturally affirming alternative to the popular meditation phone application, 
Headspace. Lastly, utilizing mindfulness skills such as awareness and non-judgment can help individuals discern which behavior would be most beneficial and intentionally responding. For example, being attuned to one's wellness needs improves the ability to recognize when and whether one needs a self-soothing behavior or needs self-care that requires community engagements is a skill set. Self-care skills are critical as they can provide Black folks a roadmap for individualizing their self-care plan and maximizing the benefits of implementing self-care behaviors.

\section{Self-care Behaviors}

Self-care behaviors are the final layer of this conceptual model and are most closely aligned with common views of self-care. The aforementioned factors that foster self-care behaviors underscore the importance of contextualizing self-care. Self-care behaviors are initiated, practiced, and sustained when attention is given to internal and external processes such as support, culture, orientation, motivation, and skills (Miller et al., 2019). It is also important to note that the engagement in and sustainability of self-care behaviors may require resources that are often inequitably distributed to communities of color. Taken together, these factors provide a capacity for one to engage or disengage in self-care behaviors. Decontextualizing self-care behaviors ignores that behaviors are embedded in other processes and structures that can either promote or hinder the practice of self-care. Furthermore, in the application of this model, Black people are encouraged to take care of their whole selves, including all areas of wellness and identity. This means giving attention to all dimensions of wellness, such as physical, emotional, social, spiritual, occupational, financial, and environmental. This also means being mindful that our whole selves are composed of multiple, intersecting identities and may be in need of individualized self-care behaviors that speak to the wellness of one identity. With this is mind, self-care behaviors for Black people might look different than what is often advertised as self-care. For example, self-care behaviors for people of color may include engaging in an ancestral practice for spiritual self-care (Pérez, 2011) or engaging in healing circles (Richardson, 2018) with other members in their communities that also encounter oppression and discrimination (Hobart \& Kneese, 2020). To this end, we believe that for Black individuals, self-care is not a behavior that must be practiced in solitude. In fact, engaging in community as a self-care behavior could be critical for people of color (French et al., 2020), given the cultural perspective on the collective's strength. There are a variety of self-care behaviors (e.g., prayer, yoga, psychotherapy, spiritual baths, having fun) that Black people and communities can choose to engage in, however, self-care is beyond behaviors or strategies of coping (Miller, 2020). Self-care is a process and practice that moves us closer to health, wellness, and liberation.

\section{Discussion}

The authors of this paper aimed to apply a model of selfcare proposed by Miller et al. (2019) to Black individuals and communities and contextualizes it within Liberation Psychology, and the theory of intersectionality. Self-care has been established in the literature as a helpful medium and process to achieve optimal wellbeing. For lay culture, self-care is often described as specific behaviors that one engages in for wellness needs. However, current self-care culture is saturated with images and messaging that perpetuates stereotypes about self-care, such as what constitutes self-care and who engages in self-care. These stereotypes can keep some populations from engaging in self-care practices and instead engage in activities or mindsets that further promote self-neglect. Given this model's applicability to various vulnerable populations, we sought to contextualize its use for better understanding self-care among Black people. While we explain each layer of the model and how it can apply to Black communities, we understand that Black people are not a monolithic group. Thus, we encourage future research and community efforts to explore the diverse ways in which self-care can be facilitated, practiced, reinforced, and promoted across this population. We conclude by offering suggestions for further research and practical recommendations for community stakeholders or community leaders.

\section{Recommendations}

\section{Research Recommendations}

Given that this model of self-care is in the stage of early development and growth, future research efforts can materialize in many forms. It is critical for future research to center the voices of Black individuals and communities to best understand the needs, especially as it relates to building self-care support and capacities that are sustainable. The authors suggest that researchers looking to study selfcare in communities of color utilize research methodology that empowers and include community key stakeholders. Qualitative research and community based participatory research (CBPR) are methodologies that redistribute the voice, power, and privileges of the communities being 
served. Data collected from qualitative focus groups and interviews can help understand how self-care is perceived and practiced in Black communities. Methodologies such as CBPR are highly valued as they create partnerships and foster collaboration with researchers, community members, and stakeholders. Additionally, CBPR can offer more equitable decision-making approaches and provide new insights about dissemination and sustainability efforts. These types of methods can also offer further empirical support for the model. Lastly, while this paper applied Miller et al. (2019) model to Black people, we believe that this conceptual model applies to marginalized populations in general. Determining the utility of this conceptual self-care framework for other minoritized or stigmatized groups such as immigrants, graduate students of color, people with serious mental illness, and returning citizens is extremely valuable. Having a comprehensive understanding of the self-care needs and perceptions among these populations could offer insight into how to encourage wellness practice and influence health outcomes.

\section{Community-Based Recommendations}

As reported in the American Psychological Association's (2020), Stress in America study, racism and discrimination continue to be a significant stressor for people of color. Seeing that self-care strategies have been implemented to cope with stress, we offer some community-based recommendations that support self-care. Community members looking to initiate or enhance community conversations about selfcare in Black neighborhoods may find this conceptual model helpful for their discourse. The proposed application of the conceptual model provides avenues for community-based programming at each layer. Community organizers can offer training on self-care or create spaces where individuals can have access to self-care activities. Community conversations that aim to position self-care as a tool for resistance and a tool for radical healing (French et al., 2020), can be useful in cultivating joy and radical hope. Health educators and community health workers embedded within communities of color can lead workshops about creating sustainable selfcare plans and teach skills to maintain self-care motivation. Community-based initiatives can also include organizing efforts to engage in self-care behaviors such as community dance classes, cooking courses, or community acupuncture sessions. Lastly, given that communities of color often combat race-based stress and racial trauma, self-care practices designed with these in mind, might be beneficial. For example, encouraging Black communities to practice restorative yoga for ethnic and race-based stress and trauma (Parker, 2020) could offer a practice specific to their wellness needs. These community-focused recommendations recognize that there are inherent strengths and wisdom in communities of color that can further facilitate the importance of engaging in self-care. They further prioritize that Black people are self-determined and can engage in self-care activities aligned with cultural values and practices that draw from ancestral wisdom.

\section{Conclusion}

Self-care is unequivocally important and necessary for all individuals, inclusive of those in Black communities. Selfcare can be a tool of resistance and preservation for Black people, given their frequent exposure to systemic oppression and discrimination. Therefore, focusing on self-care as isolated behaviors that one engages in is limiting and offers an insufficient perception of self-care. The conceptual model of self-care (Miller et al., 2019) reviewed in this paper provides a comprehensive understanding of self-care. This model addresses self-care as a process that includes support, orientation, motivation, skills, and behaviors as factors influencing one's self-care practice. Within the model, self-care is best understood through the dynamic interrelations of the abovementioned factors that can facilitate or inhibit engagement in self-care behaviors. Utilizing this comprehensive conceptual model of self-care can offer racially minoritized communities ways to implement sustainable self-care practices for their overall health and wellbeing.

Author Contributions Both authors contributed to the manuscript development. The first author had the idea for the article. The literature search and paper drafting were performed by both authors. Both authors critically revised the work.

Funding The authors have no relevant financial or non-financial interests to disclose. All authors certify that they have no affiliations with or involvement in any organization or entity with any financial interest or non-financial interest in the subject matter or materials discussed in this manuscript. The authors have no financial or proprietary interests in any material discussed in this article.

\section{Declarations}

Conflict of interest On behalf of all the authors, the corresponding author states that there is no known conflict of interest and certify that all authors are responsible for the content and the writing of this paper. The authors have no conflicts of interest to declare that are relevant to the content of this article. 


\section{References}

Addai, E. A. (2020). Taking care: Experiences with self-care among black women working for social change. Doctoral Dissertation [Retrieved from Proquest (28090992)].

American Psychological Association. (2020). Stress in America ${ }^{\mathrm{TM}}$ 2020: A National Mental Health Crisis. Retrieved December 1, 2020 from https://www.apa.org/news/press/releases/stress/2020/ report-october.

Anzaldúa, G. (1987). Borderlands = La frontera: The new mestiza . Spinsters/Aunt Lute Books.

Barnett, J. (2014). Distress, burnout, self-care, and the promotion of wellness for psychotherapists and trainees: Issues, implications, and recommendations. [Web Article]. Retrieved Decemeber 10, 2020 from http://www.societyforpsychotherapy.org/distress-thera pist-burnout-self-care-promotion-wellness-psychotherapists-train ees-issues-implications-recommendations.

Barnett, J. E., \& Cooper, N. (2009). Creating a culture of self-care. Clinical Psychology: Science and Practice, 16, 16-20. https:// doi.org/10.1111/j.1468-2850.2009.01138.x

Bell, H., Kulkarni, S., \& Dalton, L. (2003). Organizational prevention of vicarious trauma. Families in Society, 84(4), 463-470. https:// doi.org/10.1606/1044-3894.131

Bickley, J. B. (1998). Care for the caregiver: The art of self-care. Seminars in Perioperative Nursing, 7(2), 114-121.

Biggers, A., Spears, C. A., Sanders, K., et al. (2020). Promoting mindfulness in African American communities. Mindfulness, 11, 2274-2282. https://doi.org/10.1007/s12671-020-01480-w

Brownlee, E. (2016). How do counsellors view and practice self-care? Healthcare Counseling and Psychotherapy Journal, 16(6), 15-18.

Carter, L., \& Barnett, J. (2014). Self-care for clinicians in training: A guide to psychological wellness for graduate students in psychology. Oxford University Press.

Carbado, D. W., Crenshaw, K. W., Mays, V. M., \& Tomlinson, B. (2013). Intersectionality: Mapping the movements of a theory. $D u$ Bois Review: Social Science Research on Race, 10(2), 303-312.

Crenshaw, K. (1989). Demarginalizing the intersection of race and sex: A black feminist critique of antidiscrimination doctrine, feminist theory, and antiracist politics. University of Chicago Legal Forum. Retrieved December 18, 2020 from https://chicagounb ound.uchicago.edu/uclf/vol1989/iss1/8.

Carroll, L., Gilroy, P. J., \& Murra, J. (1999). The moral imperative: Self-care for women psychotherapists. Women \& Therapy, 22(2), 133-143.

Cotter, E. W., \& Jones, N. (2020). A review of Latino/Latinx participants in mindfulness-based intervention research. Mindfulness, 11, 529-553. https://doi.org/10.1007/s12671-019-01266-9

Denyes, M. J., Orem, D. E., \& Bekel, G. (2001). Self-care: A foundational science. Nursing Science Quarterly, 14(1), 48-54.

Dictionary of Politics and Government. (2004). Radical. In Dictionary of politics and government. Retrieved December 17, 2020 from http://www.untag-smd.ac.id/files/Perpustakaan_Digital_2/ POLITICS\%20AND\%20GOVERNMENT\%20Dictionary\%20\% 20politics\%20and\%20government.pdf

Dorociak, K. E., Rupert, P. A., Bryant, F. B., \& Zahniser, E. (2017). Development of a self-care assessment for psychologists. Journal of Counseling Psychology, 64(3), 325-334. https://doi.org/ $10.1037 /$ cou0000206

Evans-Hudnall, G. L., Stanley, M. A., Clark, A. N., Bush, A. L., Resnicow, K., Liu, Y., Kass, J. S., \& Sander, A. M. (2014). Improving secondary stroke self-care among underserved ethnic minority individuals: A randomized clinical trial of a pilot intervention. Journal of Behavioral Medicine, 37(2), 196-204. https://doi.org/ 10.1007/s10865-012-9469-2
Figley, C. R. (2002). Compassion fatigue: Psychotherapists' chronic lack of self care. John Wiley \& Sons Inc. https://doi.org/10.1002/ jclp. 10090

French, B. H., Lewis, J. A., Mosley, D. V., Adames, H. Y., ChavezDueñas, N. Y., Chen, G. A., \& Neville, H. A. (2020). Toward a psychological framework of radical healing in communities of color. The Counseling Psychologist, 48(1), 14-46. https://doi.org/ 10.1177/0011000019843506

Grantz, S. B. (1990). Self-care: Perspectives from six disciplines. Holistic Nursing Practice, 4(2), 1-12.

Grossman, P., Niemann, L., Schmidt, S., \& Walach, H. (2004). Mindfulness-based stress reduction and health benefits: A meta-analysis. Journal of Psychosomatic Research, 57(1), 35-43.

Harris, A. (2017). A history of self-care. Slate. Retrieved December, 16, 2020 from http://www.slate.com/articles/arts/culturebox/2017/ 04/the_history_of_self_care.html

Heynen, N. (2009). Bending the bars of empire from every ghetto for survival: The black panther party's radical Antihunger Politics of Social Reproduction and Scale. Annals of the Association of American Geographers, 99(2), 406-422.

Hooks, B. (1993). Sisters of the yam: Black women and self-recovery. South End Press.

Hill Collins, P. (1991). Black feminist thought: Knowledge, consciousness, and the politics of empowerment. Routledge.

Hill Collins, P. (2000). Black feminist thought: Knowledge, consciousness, and the politics of empowerment ( $2 \mathrm{nd}$ ed.). Routledge. https://doi.org/10.4324/9780203900055

Hobart, H. I. J. K., \& Kneese, T. (2020). Radical care survival strategies for uncertain times. Social Text, 38(1), 1-16. https://doi.org/ 10.1215/01642472-7971067

Janssen, M., Heerkens, Y., Kuijer, W., van der Heijden, B., \& Engels, J. (2018). Effects of mindfulness-based stress reduction on employees' mental health: A systematic review. PLoS ONE, 13(1), e0191332. https://doi.org/10.1371/journal.pone.0191332

Kinser, P. A., Robins, J. L. W., \& Masho, S. W. (2016). Self-administered mind-body practices for reducing health disparities: An interprofessional opinion and call to action. Evidence-Based Complementary and Alternative Medicine. https://doi.org/10. $1155 / 2016 / 2156969$

Kravits, K., McAllister-Black, R., Grant, M., \& Kirk, C. (2010). Selfcare strategies for nurses: A psycho-educational intervention for stress reduction and the prevention of burnout. Applied Nursing Research, 23(3), 130-138.

Krieger, N. (2000). Discrimination and Health. Social Epidemiology, $1,36-75$.

Lipson, J. G., \& Steiger, N. J. (1996). Self-care nursing in a multicultural context. Thousand Oaks, CA: Sage.

Lorde, A. (1984). Sister outsider. Berkeley.

Lorde, A. (1988). A burst of light. Firebrand Books.

Liberate Meditation App for Black Indigenous and People of Color. (n.d.). Retrieved December 10, 2020, from https://liberatemeditat ion.com.

Michaeli, I. (2017). Self-care: An act of political warfare or a neoliberal trap? Development, 60, 50-56. https://doi.org/10.1057/ s41301-017-0131-8

Miller, A. E. (2020). Re-thinking self-care: In grad school, in crisis \& beyond [Webinar]. American Psychology Association Minority Fellow Program.

Miller, A. E., Green, T. D., \& Lambros, K. M. (2019). Foster parent self-care: A conceptual model. Children and Youth Services Review, 99, 107-114.

Myers, S. B., Sweeney, A. C., Popick, V., Wesley, K., Bordfeld, A., \& Fingerhut, R. (2012). Self-care practices and perceived stress levels among psychology graduate students. Training and Education in Professional Psychology, 6(1), 55-66. https://doi.org/10. 1037/a0026534 
Nayak, S. (2020). For women of colour in social work: Black feminist self-care practice based on Audre Lorde's radical pioneering principles. Critical and Radical Social Work. https://doi.org/10.1332/ $204986020 X 15945755847234$

Newell, J. M., \& MacNeil, G. A. (2010). Professional burnout, vicarious trauma, secondary traumatic stress, and compassion fatigue. Best Practices in Mental Health, 6(2), 57-68.

Nicol, D. J., \& Yee, J. A. (2017). "Reclaiming our time": Women of color faculty and radical self-care in the academy. Feminist Teacher, 27(2-3), 133-156.

Palta, P., Page, G., Piferi, R. L., Gill, J. M., Hayat, M. J., Connolly, A. B., \& Szanton, S. L. (2012). Evaluation of a mindfulness-based intervention program to decrease blood pressure in low-income African-American older adults. Journal of Urban Health, 89(2), 308-316.

Pascoe, E. A., \& Smart Richman, L. (2009). Perceived discrimination and health: A meta-analytic review. Psychological Bulletin, 135(4), 531-554. https://doi.org/10.1037/a0016059

Paradies, Y. (2006). A systematic review of empirical research on selfreported racism and health. International Journal of Epidemiology, 35(4), 888-901.

Parker, G. (2020). Restorative yoga for ethnic and race-based stress and trauma. Singing Dragon.

Pearlman, L. A., \& Saakvitne, K. W. (1995). Trauma and the therapist: Counter-transference and vicarious traumatization in psychotherapy with incest survivors. Norton.

Pérez, E. (2011). Spiritist mediumship as historical mediation: AfricanAmerican pasts, black ancestral presence, and afro-cuban religions. Journal of Religion in Africa, 41(4), 330-365.

Posluns, K., \& Gall, T. L. (2020). Dear mental health practitioners, take care of yourselves: A literature review on self-care. International Journal for the Advancement of Counselling, 42(1), 1-20.

Prilleltensky, I. (2003). Understanding, resisting, and overcoming oppression: Toward psychopolitical validity. American Journal of Community Psychology, 31, 195-201. https://doi.org/10.1023/A: 1023043108210

Prilleltensky, I., \& Nelson, G. (2002). Doing psychology critically: Making a difference in diverse settings. Palgrave Macmillan.

Richard, A. A., \& Shea, K. (2011). Delineation of self-care and associated concepts. Journal of Nursing Scholarship: An Official Publication of Sigma Theta Tau International Honor Society of Nursing, 43(3), 255-264. https://doi.org/10.1111/j.1547-5069. 2011.01404.x

Richardson, J. L. (2018). Healing circles as black feminist pedagogical interventions. In Black women's liberatory pedagogies (pp. 281-294). Cham: Palgrave Macmillan.

Rivera, E. T. (2020). Concepts of liberation psychology. In L. E. Comas-Días \& T. Rivera (Eds.), Liberation psychology: Theory, method, practice, and social justice (pp. 41-52). American Psychological Association.

Rothman, A. J., Baldwin, A. S., Hertel, A. W., \& Fuglestad, P. T. (2011). Self-regulation and behavior change: Disentangling behavioral initiation and behavioral maintenance. In K. D. Vohs \& R. F. Baumeister (Eds.), Handbook of self-regulation: Research, theory, and applications (pp. 106-122). Guilford Press.

Ruggiero, L., Riley, B. B., Hernandez, R., Quinn, L. T., Gerber, B. S., Castillo, A., Day, J., Ingram, D., Wang, Y., \& Butler, P. (2014). Medical assistant coaching to support diabetes self-care among low-income racial/ethnic minority populations: Randomized controlled trial. Western Journal of Nursing Research, 36(9), 1052-1073.
Sanchez-Reilly, S., Morrison, L. J., Carey, E., Bernacki, R., O'Neill, L., Kapo, J., Periyakoil, V. S., \& Thomas, J. (2013). Caring for oneself to care for others: Physicians and their self-care. The Journal of Supportive Oncology, 11(2), 75-81. https://doi.org/10.12788/j. suponc.0003

Shapiro, S. L., Brown, K. W., \& Biegel, G. M. (2007). Teaching selfcare to caregivers: Effects of mindfulness-based stress reduction on the mental health of therapists in training. Training Andeducation in Professional Psychology, 1(2), 105.

Sheehy, C., \& Nayak, S. (2020). Black feminist methods of activism are the tool for global social justice and peace. Critical Social Policy, 40(2), 234-257. https://doi.org/10.1177/0261018319896231

Sherman D. W. (2004). Nurses' stress \& burnout. How to care for yourself when caring for patients and their families experiencing lifethreatening illness. American Journal of Nursing, 104(5), 48-57. https://doi.org/10.1097/00000446-200405000-00020

Sisk, J. E., Hebert, P. L., Horowitz, C. R., McLaughlin, M. A., Wang, J. J., \& Chassin, M. R. (2006). Effects of nurse management on the quality of heart failure care in minority communities: A randomized trial. Annals of Internal Medicine, 145(4), 273-283.

Skovholt, T., Grier, T., \& Hanson, M. (2001). Career counseling for longevity: Self-care and burnout prevention strategies for counselor resilience. Journal of Career Development, 27(3), 167-176. https://doi.org/10.1177/089484530102700303

Skovholt, T. M., Rønnestad, M. H. (2003). Struggles of the novice counselor and therapist. Journal of Career Development, 30(1), 45-58. https://doi.org/10.1177/089484530303000103

Subica, A. M., Grills, C. T., Douglas, J. A., \& Villanueva, S. (2016). Communities of color creating healthy environments to combat childhood obesity. American Journal of Public Health, 106(1), 79-86.

Suleiman-Martos, N., Gomez-Urquiza, J. L., Aguayo-Estremera, R., Cañadas-De La Fuente, G. A., De La FuenteSolana, E. I., \& Albendín-García, L. (2020). The effect of mindfulness training on burnout syndrome innursing: A systematic review and metaanalysis. Journal of Advanced Nursing, 76(5), 1124-1140. https:// doi.org/10.1111/jan. 14318

Warren-Findlow, J., \& Seymour, R. B. (2011). Prevalence rates of hypertension self-care activities among African Americans. Journal of the National Medical Association, 103(6), 503-512. https:// doi.org/10.1016/S0027-9684(15)30365-5

Webb, T. L., \& Sheeran, P. (2006). Does changing behavioral intentions engender behavior change? A meta-analysis of the experimental evidence. Psychological Bulletin, 132(2), 249-268. https://doi. org/10.1037/0033-2909.132.2.249

Williams, D. R., Neighbors, H. W., \& Jackson, J. S. (2003). Racial/ethnic discrimination and health: Findings from community studies. American Journal of Public Health, 93(2), 200-208.

Wise, E. H., Hersh, M. A., \& Gibson, C. M. (2012). Ethics, self-care and well-being for psychologists: Reenvisioning the stress-distress continuum. Professional Psychology: Research and Practice, 43(5), 487-494. https://doi.org/10.1037/a0029446

Publisher's Note Springer Nature remains neutral with regard to jurisdictional claims in published maps and institutional affiliations. 